\title{
Sequential contraction compression therapy raises foot temperatures in patients with peripheral arterial disease
}

This article was published in the following Dove Press journal:

Journal of Vascular Diagnostics and Interventions

22 September 2016

Number of times this article has been viewed

\author{
Jonathan Rosenblum' \\ Dimitry Gimmelreich ${ }^{2}$ \\ Sean Rosenblum ${ }^{3}$ \\ 'Diabetic Foot Service, Department \\ of Orthopedics, ${ }^{2}$ Department of \\ Vascular Surgery, Shaarei Zedek \\ Medical Center, Jerusalem, Israel; \\ ${ }^{3}$ Lodi, NJ, USA
}

\begin{abstract}
Sequential contraction compression therapy has been found to have a positive effect on numerous vascular conditions. The authors report the results of a pilot study looking at the effect of a sequential contraction compression device (SCCD) on patients with peripheral arterial disease (PAD). The authors evaluated ten patients with moderate PAD and treated them with one session of sequential contraction compression therapy. The primary outcome measure was a change in temperature of the foot. The authors found that there was a significant change in the foot temperatures during the treatment, which was somewhat maintained after the treatment. The results of the study indicate that there may be a place for SCCD in the treatment of PAD and that further research must be performed to validate this treatment.
\end{abstract}

Keywords: peripheral arterial disease, treatment, compression therapy

\section{Introduction}

Peripheral arterial disease (PAD) is the third most common cause of death from cardiovascular disorders, after coronary heart disease and stroke. There has been a rapid increase in the number of people with PAD over the past decade, with $\sim 202$ million people with the disease globally in $2010 .{ }^{1}$ Approximately $12 \%-16 \%$ of the population aged more than 60 years will be affected by intermittent claudication, which is a primary symptom of PAD. ${ }^{2}$ Mortality in patients who progress to critical limb ischemia (CLI) rises to $50 \%$ at 5 years; ${ }^{3}$ this is largely due to concomitant cardiovascular disease. ${ }^{4}$

Treatment goals should focus not only on the alteration of disease progression and symptomatic relief but also on the improvement of patient long-term survival. ${ }^{5}$ These include both pharmacologic therapy and open invasive as well as endovascular procedures $^{6}$; however, $\sim 25 \%$ of patients still progress each year to limb amputations. ${ }^{7}$ Other therapies for PAD and CLI include supervised exercise therapy, ${ }^{8}$ open surgical procedures, ${ }^{9}$ kinesiology, ${ }^{10}$ and electrotherapy. ${ }^{11}$

Intermittent pneumatic compression (IPC) has become a therapeutic alternative for treating both early PAD and progressive CLI. ${ }^{12,13}$ IPC works by sequentially compressing the muscles of the leg creating an upregulation in the expression of inflammatory chemokines in the compressed skeletal muscle and isolated collateral arteries, which are key factors in vascular remodeling. ${ }^{12}$ There are many problems with the use of IPC, all of which lend to poor patient compliance with the device. ${ }^{14}$ Sequential contraction compression device (SCCD) therapy addresses many of the compliance issues of IPC use. SCCD works by stimulating calf muscle contraction through a series of timed,
Correspondence: Jonathan Rosenblum Diabetic Foot Service, Department of Orthopedics, Shaarei Zedek Medical Center, 12 Shmuel Bait St, Jerusalem 9103102 , Israel

Email: diabfootman@gmail.com 
coordinated electrical pulses to the neuromuscular junction. This generates a sequential, peristaltic series of contractions from distal to proximal, stimulating enhanced blood flow in both venous return and arterial inflow.

Diagnosis of PAD is often overlooked or made after the disease has already begun to progress. ${ }^{15-17}$ Ankle-brachial index, plethysmography, and other tools have become part of the armamentarium in the diagnosis of PAD. A new technology, infrared thermography, has as late proven useful in the diagnosis of PAD. ${ }^{18}$ Because vascular integrity and function are the major determinants of cutaneous temperature, several studies have investigated its application in the detection of peripheral vascular disease. ${ }^{19}$

The authors evaluate the FlowAid FA-100, an SCCD (FlowAid Medical Technology Corp., New York, NY, USA), for its effect on raising foot temperatures in patients with PAD.

\section{Materials and methods}

The New York College of Podiatric Medicine Institutional Review Board approval was attained, and before any patient was enrolled in the study, informed consent was obtained. A total of ten patients were evaluated for this study. All the ten were chronic patients in the vascular clinic at our institution. The patients who met the inclusion criteria for the study were selected sequentially from a list that was generated. All the ten had type 2 diabetes mellitus for a minimum of 10 years. All patients were aged between 55 years and 75 years, and all had a history of smoking at least one pack per day for more than 20 years. All patients had an ankle-brachial index between 0.55 and 0.70 . There were seven males and three females. Although all of the patients were claudicants, none of the patients were eligible surgical candidates. All the ten patients were being pharmacologically managed for their underlying cardiovascular diseases as well as their symptomatology. None of the patients had undergone an amputation in either foot. Table 1 shows the demographic data of the subjects.

Table I Demographic data of the patients

\begin{tabular}{lll}
\hline Patient number & Sex & Age (years) \\
\hline 1 & Male & 72 \\
2 & Male & 63 \\
3 & Female & 75 \\
4 & Male & 59 \\
5 & Female & 64 \\
6 & Male & 71 \\
7 & Male & 58 \\
8 & Female & 66 \\
9 & Male & 67 \\
10 & Male & 73 \\
Average & & 66.8 \\
\hline
\end{tabular}

Patients were brought into the examination room and put in a reclining chair in a comfortable position. Temperature in the room was controlled and kept at $21^{\circ} \mathrm{C}$. Patients were asked to rest for 20 minutes before commencement of the evaluation. Infrared thermography was performed using a handheld FLIR EX 320 Infrared camera. Images were taken every 2 minutes for the duration of the intervention with the SCCD and for 1 hour after completion of the treatment. Measurements were taken at a number of points on the foot including in the plantar arch, the lateral aspect of the heel, and on the dorsum of the forefoot around the third metatarsophalangeal joint. Table 2 shows the initial temperatures in these three areas.

Therapeutic intervention included use of the FlowAid FA-100 SCCD set to the arterial setting. The SCCD is a self-contained device that stimulates contraction of the calf muscles via application of four electrodes to the posterior of the leg (Figure 1). The devices were activated and the

Table 2 Initial foot temperatures $\left({ }^{\circ} \mathrm{C}\right)$

\begin{tabular}{llll}
\hline Patient number & Plantar arch $\left({ }^{\circ} \mathbf{C}\right)$ & Heel $\left({ }^{\circ} \mathbf{C}\right)$ & Forefoot $\left({ }^{\circ} \mathbf{C}\right)$ \\
\hline 1 & 31.1 & 28.9 & 27.6 \\
2 & 28.3 & 27.3 & 24.4 \\
3 & 29.7 & 29.4 & 27.2 \\
4 & 26.4 & 26.2 & 26.1 \\
5 & 27.1 & 25.3 & 24.4 \\
6 & 27.3 & 23.4 & 21.3 \\
7 & 28.4 & 24.4 & 19.8 \\
8 & 30.2 & 28.4 & 25.7 \\
9 & 29.9 & 28.2 & 22.2 \\
10 & 30.6 & 27.1 & 26.3 \\
Average (SD) & $28.90(1.62)$ & $26.86(2.00)$ & $24.50(2.62)$ \\
\hline
\end{tabular}

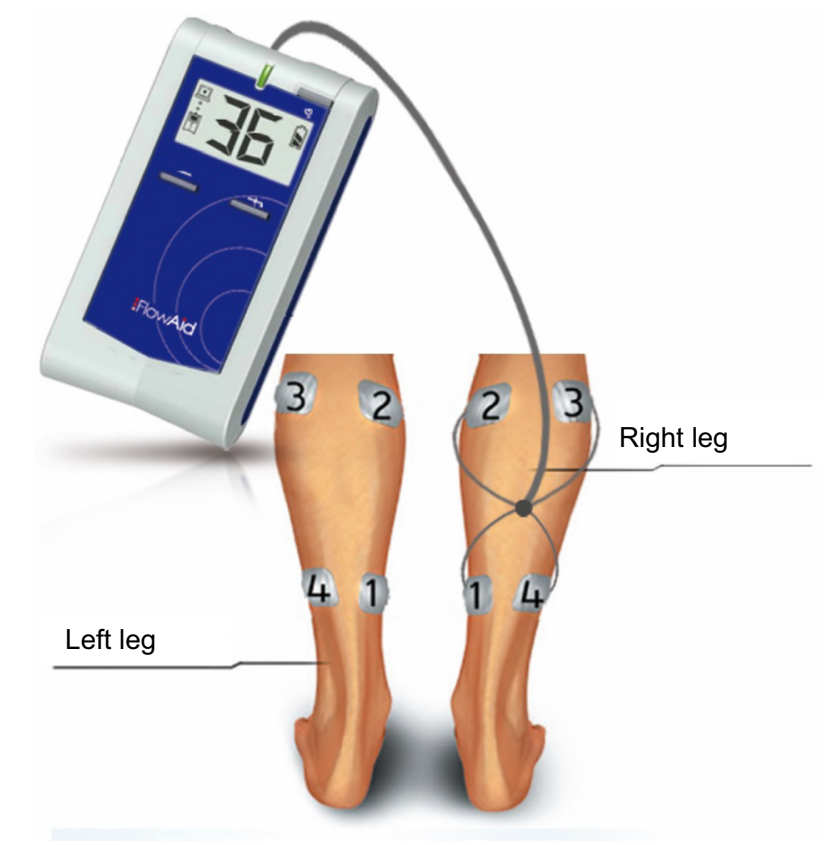

Figure I Demonstration of application of SCCD.

Abbreviation: SCCD, sequential contraction compression device. 


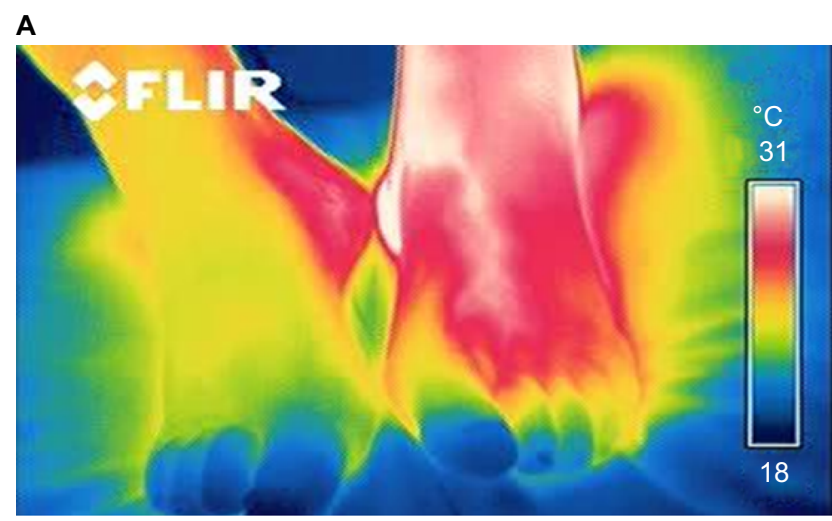

B

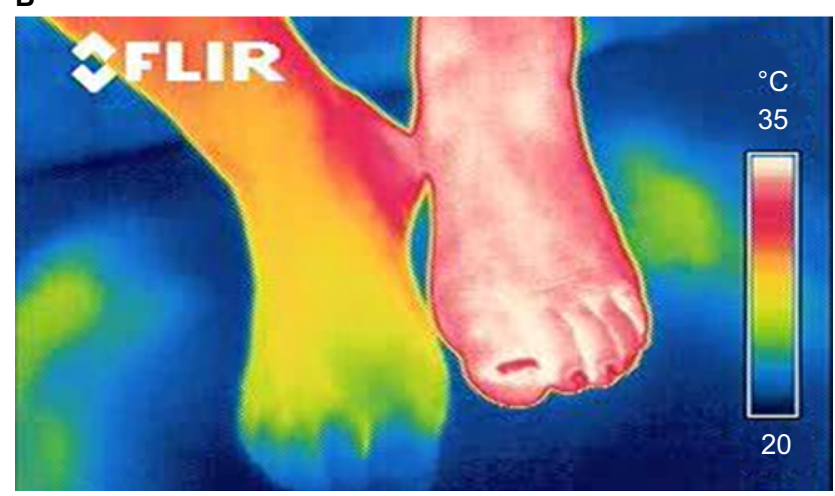

Figure 2 Infrared thermography before and after treatment with the SCCD Note: (A) Before and (B) after, treated (left) and nontreated (right) legs. Abbreviation: SCCD, sequential contraction compression device.

intensity was raised until visible contractions were seen or the patient reached their tolerance level for the electrical impulse. Patients were then given the device and advised that the higher the intensity, the better the results would be, but there was no need to raise it until uncomfortable.

Digital infrared thermography was performed continuously during the evaluation and was performed to both legs to establish a baseline standard for change and to control for changes due to room temperature.

The results of the changes in temperature were recorded and subjected to statistical analysis, including mean data, calculation of standard deviations, and an evaluation to calculate confidence intervals at $95 \%$.

Figure $2 \mathrm{~A}$ and $\mathrm{B}$ demonstrates the example of the infrared thermography before and after treatment with the SCCD.

\section{Results}

Tables 2 and 3 show the changes in temperatures after use of the SCCD. Use of the FlowAid FA-100 device for 2 hours increased the measured temperatures in all subjects. In the area of the plantar arch, where the changes generated by flow in the plantar arteries were measured, there was an average increase of $4.23^{\circ} \mathrm{C}$. In the heel, the average change in temperature was
Table 3 Changes in foot temperatures after treatment with $\operatorname{SCCD}\left({ }^{\circ} \mathrm{C}\right)$

\begin{tabular}{lllll}
\hline $\begin{array}{l}\text { Patient } \\
\text { number }\end{array}$ & $\begin{array}{l}\text { Plantar } \\
\text { arch } \\
\pm\left({ }^{\circ} \mathbf{C}\right)\end{array}$ & $\begin{array}{l}\text { Heel } \\
\pm\left({ }^{\circ} \mathbf{C}\right)\end{array}$ & $\begin{array}{l}\text { Forefoot } \\
\pm\left({ }^{\circ} \mathbf{C}\right)\end{array}$ & $\begin{array}{l}\text { Time to } \\
\text { maximum } \\
\text { temperature } \\
\text { (minutes) }\end{array}$ \\
\hline $\mathrm{I}$ & +2.9 & +2.1 & +3.0 & 108 \\
2 & +5.1 & +5.4 & +5.5 & 68 \\
3 & +2.7 & +2.4 & +3.2 & 114 \\
4 & +4.8 & +5.1 & +5.8 & 92 \\
5 & +4.6 & +7.0 & +6.2 & 74 \\
6 & +3.9 & +4.7 & +4.7 & 82 \\
7 & +4.1 & +5.3 & +5.1 & 68 \\
8 & +4.1 & +4.6 & +5.3 & 68 \\
9 & +4.8 & +6.0 & +5.9 & 70 \\
I0 & +5.3 & +6.4 & +6.3 & 54 \\
Average (SD) & $+4.23(0.88)$ & $+4.90(\mathrm{I} .58)$ & $+5.10(\mathrm{I} .16)$ & $79.80(19.24)$ \\
\hline
\end{tabular}

Abbreviation: SCCD, sequential contraction compression device.

$4.90^{\circ} \mathrm{C}$, and in the forefoot the change was $5.10^{\circ} \mathrm{C}$. The pattern of change was almost uniform across subjects, with the arch showing warming first, followed by the heel, and then the toes. The average time to reach maximum increase was 80 minutes. There was a gradual decrease in temperatures over the hour of rest after the device was removed.

Paired sample $t$-tests were used to compare the temperatures of the arch, heel, and foot before and after the treatment. All $t$-tests were significant at the 0.001 level: arch (mean change $=4.23$, standard error $[\mathrm{SE}]=0.28 ; t(9)=15.2, P<0.001)$, heel (mean change $=4.9, \mathrm{SE}=0.5 ; t(9)=9.8, P<0.001$ ), and foot (mean change $=5, \mathrm{SE}=0.36 ; t(9)=13.9, P<0.001$ ).

There was a negative correlation between the duration of time to achieve maximum temperature and the absolute degree of the effect of the SCCD on the temperature change. The results were independent of sex and age. The sample size did not allow for a correlation with severity or duration of diagnosed PAD.

\section{Discussion}

This study used skin temperature of the extremity as a measure of adequate circulation. The relationship between blood flow and surface temperature was identified in $1993 .{ }^{20}$ Because the temperature of extremities is largely dependent on peripheral blood flow vessels, measurement of skin temperature is useful in vascular diseases. ${ }^{21}$

This was a pilot study with all the benefits and limitations of such a study. The number of subjects was small, and this affects the statistical outcome of the study. We were able to get a homogenous group of patients, all with diabetes, a history of smoking, and similar severity of their PAD. 
The results of our study compared well with other interventions for PAD. Rabin et $\mathrm{al}^{22}$ showed an increase of $1.9^{\circ} \mathrm{C}$ in a study of preprogrammed oscillations on 15 patients. The results were also in line with those found by Kerschan-Schindl et al. ${ }^{23}$

The rise in foot temperature can be attributed to a number of factors. First is the influx of fresh blood to previously ischemic areas. This is consistent with other studies that correlated temperature findings with other tests of microvasculature. $^{22,23}$ By showing that local flow was increased with laser Doppler and Trans Cutaneous Oxygen Pressure $\left(\mathrm{TCPO}_{2}\right)$ and a simultaneous increase in skin temperature over those measured areas, we can understand that the temperature is directly correlated with the flow and its perfusion of the skin.

Temperature elevation, were it to occur in the area of electrical stimulation, contraction, or compression, could be attributed to muscle exertion and the effect of work. Because the measurements were conducted at a relative distance from the area of contraction, the temperature elevation found in this study should not be attributed to this.

With the limitations of this study noted, the authors recommend a controlled trial on a larger group of subjects. Future studies can focus on the time to hit maximum temperature increase and if that has an effect on the overall treatment. Evaluation should also be directed at determining which factors in the SCCD are most responsible for the temperature elevation. Correlation with quality of life and claudication would also be important factors to evaluate.

\section{Conclusion}

Although the sample size was small, SCCD therapy shows promise as an adjunct therapy for the treatment of PAD. A randomized controlled trial is highly recommended to further evaluate this technology and infrared thermography would be an excellent measure of increased blood flow to the extremity.

\section{Disclosure}

The authors report no conflicts of interest in this work.

\section{References}

1. Fowkes FGR, Rudan D, Rudan I, et al. Comparison of global estimates of prevalence and risk factors for peripheral artery disease in 2000 and 2010: a systematic review and analysis. Lancet. 2013;382(9901): 1329-1340.

2. Criqui MH, Fronek A, Barrett-Connor E, Klauber MR, Gabriel S, Goodman D. The prevalence of peripheral arterial disease in a defined population. Circulation. 1985;71(3):510-515.
3. Dormandy JA, Heeck L, Vig S. The fate of patients with critical leg ischemia. Semin Vasc Surg. 1999;12(2):142-147.

4. Criqui MH, Langer RD, Fronek A, et al. Mortality over a period of 10 years in patients with peripheral arterial disease. $N$ Engl $J$ Med. 1992;326(6):381-386.

5. Dormandy JA, Rutherford RB. Management of peripheral arterial disease (PAD). TASC Working Group. TransAtlantic Inter-Society Consensus (TASC). J Vasc Surg. 2000;31(1 pt 2):S1-S296.

6. Hioki H, Miyashita Y, Miura T, et al. Prognostic improvement by multidisciplinary therapy in patients with critical limb ischemia. Angiology. 2015;66(2):187-194.

7. Henry AJ, Hevelone ND, Belkin M, Nguyen LL. Socioeconomic and hospital-related predictors of amputation for critical limb ischemia. $J$ Vasc Surg. 2011;53(2):330-339.e1.

8. Aherne T, McHugh S, Kheirelseid EA, et al. Comparing supervised exercise therapy to invasive measures in the management of symptomatic peripheral arterial disease. Surg Res Pract. 2015;2015:960402.

9. Sun N, Tian A, Tian Y, Hu S, Xu L. The interventional therapy for diabetic peripheral artery disease. BMC Surg. 2013;13:32.

10. Bell JW, Chen D, Bahls M, Newcomer SC. Altered resting hemodynamics in lower-extremity arteries of individuals with spinal cord injury. $J$ Spinal Cord Med. 2013;36(2):104-111.

11. Anderson SI, Whatling P, Hudlicka O, Gosling P, Simms M, Brown MD. Chronic transcutaneous electrical stimulation of calf muscles improves functional capacity without inducing systemic inflammation in claudicants. Eur J Vasc Endovasc Surg. 2004;27(2):201-209.

12. Roseguini BT, Arce-Esquivel AA, Newcomer SC, Laughlin MH. Impact of a single session of intermittent pneumatic leg compressions on skeletal muscle and isolated artery gene expression in rats. $\mathrm{Am} J$ Physiol Regul Integr Comp Physiol. 2011;301(6):R1658-R1668.

13. Roseguini BT, Arce-Esquivel AA, Newcomer SC, Yang HT, Terjung $\mathrm{R}$, Laughlin $\mathrm{MH}$. Intermittent pneumatic leg compressions enhance muscle performance and blood flow in a model of peripheral arterial insufficiency. J Appl Physiol. 2012;112(9):1556-1563.

14. Delis KT, Nicolaides AN. Effect of intermittent pneumatic compression of foot and calf on walking distance, hemodynamics, and quality of life in patients with arterial claudication: a prospective randomized controlled study with 1-year follow-up. Ann Surg. 2005;241(3):431-441.

15. O'Donnell M, Reid J, Lau L, Hannon R, Lee B. Optimal management of peripheral arterial disease for the non-specialist. Ulster Med J. 2011;80(1):33-41.

16. El-Menyar A, Al Suwaidi J, Al-Thani H. Peripheral arterial disease in the Middle East: underestimated predictor of worse outcome. Global Cardiol Sci Pract. 2013;2013(2):98-113.

17. Barochiner J, Aparicio LS, Waisman GD. Challenges associated with peripheral arterial disease in women. Vasc Health Risk Manag. 2014;10:115-128.

18. Huang CL, Wu YW, Hwang CL, et al. The application of infrared thermography in evaluation of patients at high risk for lower extremity peripheral arterial disease. J Vasc Surg. 2011;54(4):1074-1080.

19. Bagavathiappan S, Saravanan T, Philip J, et al. Infrared thermal imaging for detection of peripheral vascular disorders. J Med Phys. 2009;34(1):43-47.

20. Wu JY. Thermogram analysis and its clinical application, Master Thesis, National Cheng Jung University. ROC, Tainan, Taiwan, 1995.

21. Herrick L, Hutchinson C. Vascular imaging. Best Pract Res Clin Rheumatol. 2004;18(6):957-979.

22. Rabin I, Shpolanski U, Leibovitz A, Bass A. Preprogrammed oscillations improve lower limb blood flow and walking distance in patients with peripheral arterial disease. Isr Med Assoc J. 2014;16(7):423-426.

23. Kerschan-Schindl K, Grampp S, Henk C, et al. Whole-body vibration exercise leads to alterations in muscle blood volume. Clin Physiol. 2001;21(3):377-382. 
The Journal of Vascular Diagnostics and Interventions is an international, peer-reviewed journal of diagnostics, focusing on non invasive vascular investigation methods involved in the evaluation of vascular diseases. The journal is committed to the rapid publication in the fields of vascular diseases. Original research, review, case reports, expert opinion and commentaries are all considered for publication. The manuscript management system is completely online and includes a very quick and fair peer-review system, which is all easy to use. Visit http://www.dovepress.com/testimonials.php to read real quotes from published authors.

Submit your manuscript here: https://www.dovepress.com/journal-of-vascular-diagnostics-journal 